\title{
TRABALHADOR-PESQUISADOR: ANÁLISE DA IMPLICAÇÃO COMO RESISTÊNCIA AO DISTANCIAMENTO DO OBJETO
}

WORKER-RESEARCHER: ANALYSIS OF IMPLICATION AS RESISTANCE TO OBJECT DISTANCING TRABAJADOR-INVESTIGADOR: ANÁLISIS DE IMPLICACIÓN COMO RESISTENCIA AL DISTANCIAMIENTO DEL OBJETO

\section{Cláudia Maria Filgueiras Penido*}

\begin{abstract}
RESUMO
Cada vez mais profissionais procuram pós-graduações para estudar situações relacionadas a seu próprio trabalho. Apesar disso, há escassez de estudos que analisem a singularidade dessa condição de produção de pesquisa. Com base em René Lourau, pretende-se, neste ensaio, discutir a análise da implicação como possibilidade de explorar a potência do trabalhador-pesquisador na atividade científica, em vez do distanciamento do objeto como condição. Ao final, aponta-se a escrita diarística como um possível dispositivo para o agenciamento da análise coletiva da implicação do trabalhador-pesquisador.
\end{abstract}

Palavras-chave: Trabalhador-pesquisador. Análise institucional. Análise da implicação.

\begin{abstract}
Professionals are increasingly looking for postgraduate degrees to study issues related to their own work. Nevertheless, there is a lack of studies analyzing the uniqueness of this condition of producing research. Based on René Lourau, this essay aims at discussing the analysis of implication, as a possibility to explore the worker-researcher's potential in scientific activity, instead of the distancing from the object, as a condition. At the end, the diary writing is pointed out as a possible device for managing the workerresearcher's collective implication analysis.
\end{abstract}

Keywords: Worker-researcher. Institutional analysis. Implication analysis.

\section{RESUMEN}

Cada vez más, los profesionales buscan posgrados para estudiar situaciones relacionadas con su propio trabajo. Sin embargo, hay pocos estudios que analizan la singularidad de esta condición de producción de investigación. A partir de René Lourau, este ensayo tiene como objetivo discutir el análisis de

"Professora no Programa de Pós-Graduação em Psicologia da Universidade Federal de Minas Gerais (UFMG). E-mail: 
la implicación como una posibilidad para explorar el poder del trabajadorinvestigador en la actividad científica, en lugar del distanciamiento del objeto como condición. Al final, la escritura del diario se señala como un posible dispositivo para el agenciamiento del análisis colectivo de la implicación del trabajador-investigador.

Palabras clave: Trabajador-investigador. Análisis institucional. Análisis de la implicación.

\section{INTRODUÇÃO}

É frequente que profissionais do campo das Ciências Humanas e Sociais tenham a oportunidade de atuar nas políticas públicas (Torres \& Lanza, 2013; Silva \& Carvalhaes, 2016). Por diversos motivos, não raro eles buscam espaços de formação para refletirem e pesquisarem sobre seu trabalho. Uma das demandas que dirigem à academia é a de acessar um mundo profissional conhecido por meio de referenciais teórico-metodológicos distintos que lhes permitam olhá-lo de outra forma, como um mundo estranho (Lavergne, 2007). A situação descrita configura um tipo de pesquisador específico, que, no âmbito deste artigo, chamaremos trabalhador-pesquisador.

Apesar de a presença desses trabalhadores-pesquisadores ser muito comum nas pós-graduaçôes lato e stricto sensu, com destaque para os mestrados profissionais, nota-se que tal condição muitas vezes não é levada em conta, como se o fato de se reconhecer tal especificidade fosse denunciar um caráter não científico à pesquisa que realiza.

Ao contrário, defendo que a condição de trabalhador-pesquisador deve ser explorada ao máximo nas pesquisas em que isso é uma realidade. Perscrutar tal situação não se pauta por um furor que se pretenda esterilizador de possíveis máculas à tarefa científica, mas se sustenta na aposta de que a condição de trabalhador-pesquisador é um operador potente na dinâmica do processo investigativo. Com Albarello (2004), parto do pressuposto de que "o engajamento, a participação, a presença e a ancoragem representam um inegável trunfo que o trabalhador, quando se constitui trabalhador-pesquisador, poderá explorar de forma muito favorável” (p. 18, tradução nossa). Entretanto, discordando em parte do mesmo autor, sustento que o distanciamento não se coloque como uma condição para o fazer científico.

Pretende-se, neste ensaio, com base no referencial teórico da análise institucional em René Lourau, discutir a análise da implicação como possibilidade de explorar a potência do trabalhador-pesquisador na atividade científica, em 
vez do distanciamento do objeto como condição. Ao final, aponta-se a escrita diarística como um possível dispositivo para o agenciamento da análise coletiva da implicação do trabalhador-pesquisador.

O termo trabalhador-pesquisador é uma tradução livre da expressão francesa praticien-chercheur, encontrada na maior parte dos textos de referência para este ensaio. É preciso explicitar, entretanto, algumas dificuldades relativas à opção por tal tradução. O problema se refere ao vocábulo praticien, que diz respeito à pessoa que conhece a prática de uma arte ou técnica (Rey, 1988), o que não configura necessariamente uma atuação profissional. Como este artigo não se resume a discutir a especificidade de um profissional que faz uma pesquisa, mas se refere a um profissional atuante cuja prática de trabalho compõe seu objeto de pesquisa, optei por enfatizar mais a ideia do trabalho do que a da profissão, embora a profissão seja condição para desenvolver seu trabalho.

Apesar do exposto, reconheço outras traduções possíveis. Uma delas, "práticopesquisador" (Jesus, Michinel, \& Burnham, 2012; Altarugio \& Capecchi, 2016), tem sido mais usada na área da Educação. Também há a tradução "profissionalpesquisador", como preferido por Fortuna, Matumoto, Mesquita e Monceau (2016), muito embora esses autores também utilizem, no mesmo artigo, a expressão trabalhador-pesquisador. Em outras publicaçōes, já utilizamos o termo trabalhador-pesquisador (Penido \& Machado, 2017; Penido \& Passos, 2019), embora o tema tenha sido tratado de forma secundária. Também há, no Brasil, uma publicação em francês que usa o termo praticien-chercheur. É o caso de artigo escrito por uma autora francesa e publicado na revista Fractal (Saint-Martin, 2013). Dos artigos encontrados, esse é o único que aborda, de modo mais central, a situação do trabalhador-pesquisador, com base em uma experiência de pesquisa em meio escolar na França.

De toda forma, no Brasil, são escassos os estudos que abordam o estatuto do trabalhador-pesquisador, ainda que sob as outras designações expostas acima. Nesse cenário restrito, é comum que os interessados na temática recorram a dois tipos de publicação: livros de metodologia científica que abordam a relação "sujeito-objeto", muitas vezes de forma circunscrita, superficial e prescritiva, ou trabalhos do campo da Antropologia sobre a condição do "pesquisador-nativo", tais como os de Zaluar (1986) e Silva (2007). Portanto este artigo também se justifica com base nessas lacunas na literatura brasileira.

Embora de forma não consciente, este ensaio começou a ser gestado anos atrás, quando eu coordenava equipes de apoio matricial em saúde mental na Atenção Primária à Saúde, em um Município de médio porte da Região Metropolitana de Belo Horizonte. Na época, decidi pesquisar meu próprio trabalho (Penido, 
2012), o que me permitiu experimentar algumas dificuldades e desafios como trabalhadora-pesquisadora. Atualmente, embora não seja mais uma trabalhadora do "chão de práticas", percebo que me deixei afetar indelevelmente por aquela experiência, que, de alguma forma, faz-se presente neste texto.

\section{O TRABALHADOR-PESQUISADOR}

Diferentemente do Brasil, em países de língua francesa, muitos são os trabalhos sobre o tema do trabalhador-pesquisador (praticien-chercheur). Entre vários, citamos Kohn (2001); Albarello (2004); Drouard (2006); Lavergne (2007); Saint-Martin, Pilotti e Valentim (2014). Há também teses sobre o assunto, uma delas defendida pela brasileira Dalpiaz, em 1994, na Universidade de Paris VIII (Dalpiaz, 2017).

Inicialmente, para melhor delinear o estatuto do trabalhador-pesquisador, retomo as contribuições de três desses autores: Lavergne (2007), Kohn (2001) e Albarello (2004), ressaltando, neste último, um ponto de sua argumentação que penso exigir uma discussão específica, o que será feito no próximo tópico.

Lavergne (2007) constrói uma das definições mais abrangentes e explícitas sobre o trabalhador-pesquisador, considerado como "um profissional e um pesquisador que conduz sua pesquisa no local em que atua profissionalmente ou em outro próximo, que guarde similaridades ou laços com seu ambiente ou seu domínio de atividade" (p. 28, tradução nossa). Defende que trabalhador-pesquisador agrupa "questionamentos de ordem epistemológica, ética e metodológica sobre a pesquisa qualitativa", colocando em análise "as formas de reconhecimento e de avaliação da subjetividade de todo pesquisador" e questionando "a relação e a demarcação entre o mundo científico e o mundo profissional” (p. 28, tradução nossa). Propõe, nesse sentido, que não só "a atividade profissional gere e oriente a atividade de pesquisa, mas também, de forma dialógica e recursiva, que a atividade de pesquisa renove e reoriente a profissional” (p. 29, tradução nossa).

Kohn (2001), outra autora francesa, considera que o trabalhador-pesquisador é um caso-limite que reivindica uma dupla postura sem que uma se sobreponha à outra, o que se expressa claramente no traço que une os dois termos de maneira igualitária. Segundo ela, se a expressão fosse "trabalhador pesquisador" (sem hífen) o termo "pesquisador" seria um qualificativo apensado ao estatuto de pesquisador. Por outro lado, se a expressão fosse "pesquisador trabalhador", a qualidade de trabalhador seria apensada ao estatuto de pesquisador. $\mathrm{O}$ traço de união da expressão trabalhador-pesquisador, portanto, marca uma distância 
imperceptível e, ao mesmo tempo, incomensurável, uma vez que as menores distâncias são intransitáveis (Casellas-Ménière, 2001).

Com base em Barel (1982a; 1982b), Kohn (2001) aponta a situação paradoxal do trabalhador-pesquisador, estatuto que tanto inclui uma unidade quanto a identidade dos contrários. Segundo ela, o fato de um ator desejar, ao mesmo tempo, uma coisa e seu contrário marca o paradoxo em questão. A dupla estratégia, nesse sentido, é uma resposta lógica a uma situação que é, em si, conflituosa ou contraditória.

A partir do exposto, Kohn (2001) indica haver três posições possíveis ao trabalhador-pesquisador. De forma sintética, na primeira, trabalhador e pesquisador aparecem, de forma separada, no tempo, espaço e ação. Privilegia-se um como se o outro não existisse, mas o outro continua a funcionar apesar disso. $\mathrm{Na}$ segunda, trabalhador e pesquisador se alternam em movimento oscilatório, reforçando a ligação entre ambos. $\mathrm{Na}$ terceira, trabalhador e pesquisador são simultâneos no tempo, espaço e na mesma pessoa, em um emaranhado hierárquico. Lavergne (2007), em esforço de síntese das três posiçōes descritas por Kohn (2001), nomeia a primeira como suspensão; a segunda como oscilação pendular; e a terceira como gestão dialógica.

Kohn (2001) argumenta, finalmente, que a postura do trabalhadorpesquisador é uma escolha que significa o reconhecimento de dois estatutos. Trata-se de uma mesma pessoa tomando variadas posiçôes de acordo com os momentos, os objetivos, as funções e o contato com os outros. Lavergne (2007) nota, sobre Kohn (2001), que os termos utilizados por esta autora, tais como entrelaçamento ou emaranhamento, indicam que as posições de trabalhador ou pesquisador não são simplesmente alternantes, mas vividas em sincronicidade:

O pesquisador não deixa o trabalhador no vestiário, e vice-versa. Quando ele se engaja em uma prática, ele também mobiliza as observaçôes e as análises do pesquisador. De qualquer forma, o pesquisador não quer abandonar sua posição inicial, ignorá-la ou desprezá-la. Consequentemente, ele mistura os limites instituídos (Lavergne, 2007, p. 33, tradução nossa).

Acrescento que o trabalhador-pesquisador não pode ser reconhecido como resultante da soma dos estatutos de trabalhador e pesquisador relativos a um mesmo indivíduo. Os pressupostos epistemológicos representados na máxima "transformar para conhecer" inspiram o debate: se eu transformo para conhecer, ao mesmo tempo em que transformo, conheço e, conhecendo, sigo transformando. Nesse sentido, seria impossível isolar o trabalhador em relação ao pesquisador e vice-versa, uma vez que o trabalhador-pesquisador assume a radicalidade do movimento. 
Já o belga Albarello, em publicação de cunho metodológico (Albarello, 2004), parte do pressuposto que o trabalhador-pesquisador tanto se inscreve em uma hierarquia organizacional, cumpre tarefas e presta contas de suas ações e práticas profissionais quanto necessita compreender a origem de um fenômeno ou descrever, da melhor maneira possível, a modalidade de funcionamento de um sistema, o que lhe exige lidar com a tensão entre dois modelos aparentemente irreconciliáveis: da ação e da pesquisa. Ele reconhece que um mesmo ator pode ocupar simultaneamente as posições de trabalhador e pesquisador, porém sem as confundir.

De forma geral, o autor defende que engajamento e a participação no campo de pesquisa é um trunfo a ser explorado pelos trabalhadores-pesquisadores. Segundo ele, o engajamento traz força e originalidade às pesquisas que conduzem, por lhes permitir, por exemplo, escutar a pulsação das instituições, perceber zonas de sombra, efeitos perversos e aspectos simbólicos de interesse, ainda que não acessíveis em um primeiro olhar (Albarello, 2004). Apesar dessa defesa, entretanto, o autor postula a necessidade de distanciamento, de forma a permitir ao pesquisador "outro olhar sobre a realidade" (Albarello, 2004, p. 17, tradução nossa). Segundo ele, engajamento e distanciamento seriam complementares e seria necessário um esforço de equilíbrio dialético entre tais polos.

Albarello (2004) busca em Elias (1983) os conceitos de engajamento e distanciamento para postular a necessidade de o trabalhador-pesquisador operar um equilíbrio dialético entre esses polos. O polo do engajamento é caracterizado pelo subjetivo, irracional e imaginário, em contraste com o polo do distanciamento, que se diferencia pelo objetivo, pelo racional, pelo pensamento e pelo controle. Segundo Albarello (2004), Elias mostra

Que foi no esforço permanente de tender para o distanciamento, isto é, para a compreensão e o controle, que as sociedades humanas puderam, progressivamente, de maneira ainda incompleta, ganhar pouco a pouco os combates contra as forças da natureza (p. 16, tradução nossa).

Diferentemente de Elias, que se dispôs a analisar a problemática do engajamento e distanciamento na relação entre Estados, Albarello (2004) se apropria dos conceitos para abordar a problemática microssocial da metodologia de pesquisa em Ciências Humanas, sobretudo quando conduzidas por trabalhadores-pesquisadores. A tese é de que "o distanciamento é alcançado não pelo pertencimento a um mundo qualquer que seja, mas pela dinâmica de um processo de aquisição progressiva de competências e de adoção de procedimentos" (Albarello, 2004, p. 19, tradução nossa). No caso do trabalhador-pesquisador, a competência que mais frequentemente necessita ser adquirida é a de se "afastar 
do polo do engajamento para se dirigir ao do distanciamento. Isso significa que é indispensável passar dos modelos e critérios de ação aos modelos e critérios da pesquisa" (Albarello, 2004, p. 26, tradução nossa).

É certo que Albarello (2004) não toma o distanciamento como meta rígida e isolada, mas em situação de movimento dialético em relação ao engajamento. Apesar disso, no intuito de ampliar a discussão, proponho, em contraposição ao distanciamento, o exame da questão com base na perspectiva institucionalista de Lourau, com ênfase na proposta da análise da implicação (Lourau, 2004c). Parto do princípio de que a demanda de distanciamento em relação ao objeto, mais fortemente endereçada, no meio acadêmico, ao trabalhador-pesquisador, sustenta-se no pressuposto da neutralidade científica, ponto que abordarei a seguir.

\section{ANÁLISE DA IMPLICAÇÃO DO TRABALHADOR- PESQUISADOR:NEMENGAJAMENTONEMDISTANCIAMENTO}

O conceito de implicação começou a ser trabalhado por Lourau e Lapassade em suas intervençôes socioanalíticas. Eles acreditavam que, ao provocar uma análise de implicação, a análise da instituição poderia se realizar (Monceau, 2008). Embora a implicação seja um conceito cujo surgimento remonta às décadas de 1960 e 1970, no plano teórico, ele sofreu mudanças ao longo do tempo e, somente na década de 1980, manifestou ligação mais orgânica com o paradigma institucionalista (Lourau, 2004a).

Em seu livro Lapsus des intellectuels, Lourau (1981) alertou para uma lacuna ou um lapso ideológico dos intelectuais no que se refere a analisarem seus lugares na reprodução das relações sociais e na sobrevivência do sistema de opressão. Segundo ele, a implicação é

O conjunto de relações que o intelectual recusa, conscientemente ou não, analisar sobre as relaçôes com seus objetos de estudo, com a instituição cultural, com sua família ou outra, com o dinheiro, com o poder, com a libido e, em geral, com a sociedade da qual ele faz parte (Lourau, 1981, p. 24, tradução nossa).

De forma geral, pode-se dizer que a implicação, em Lourau, diz respeito à relação do indivíduo com as instituições, ponto a que chegou em um de seus últimos trabalhos:

A implicação não é, cada vez mais claramente, o objeto de análise das relações que nós mantemos com a instituição - e, em primeiro lugar, com a instituição de pertencimento mais próxima que torna possível nossa inserção nas situações sociais de intervenção, de formação, de pesquisa? (Lourau, 1996, p. 14, tradução nossa) 
A instituição se caracteriza pelo movimento das instâncias denominadas instituído (tais como valores e modos de representação estabelecidos como normais ou esperados) e instituinte (caracterizada pelas forças inovadoras e contestatórias), que se colocam em tensionamentos dialéticos no processo de institucionalização. Para Lourau (1993), a "instituição não é um conceito descritivo: não designa coisas passíveis de serem vistas, sólidas, concretas” (p. 61). Ela atravessa e funde todos os níveis da estrutura social, definindo-se pela transversalidade. Interessa ao autor "utilizar a noção de instituição como campo de análise [. . .] um artifício, um modelo teórico que permite compreender o que se passa numa casa, escola, hospital, fábrica, bairro, cidade" (Lourau, 1993, p. 61).

Concordo com Lavergne (2007) sobre o trabalhador-pesquisador chacoalhar os limites instituídos, tornando-se ele mesmo um elemento analisador. Para Lourau (2004d), o analisador tanto dissolve o saber instituído, o que gera um efeito revelador, quanto modifica as relações de força constitutivas das formas de representação instituída, o que dispara um efeito político catalisador de mudanças. Para efeito deste ensaio, considero o trabalhador-pesquisador como um dispositivo que produz movimentos instituintes e faz falar algumas instituições, entre elas a própria ciência.

No caso do trabalhador-pesquisador, o fato de conduzir sua pesquisa no local em que atua profissionalmente ou em outro próximo, que guarde similaridades ou laços com seu ambiente ou seu domínio de atividade (Lavergne, 2007), é o que muitas vezes torna possível sua inserção naquela situação social de pesquisa. Entretanto a proximidade que facilita o acesso traz, ao mesmo tempo, desafios em relação à suposta necessidade de distanciamento em relação ao objeto de pesquisa.

A desnaturalização da neutralidade analítica é um dos pontos que a implicação permite ampliar em relação ao exposto acima:

A implicação deseja pôr fim às ilusões e imposturas da "neutralidade" analítica, herdadas da psicanálise e, de modo mais geral, de um cientificismo ultrapassado, esquecido de que, para o "novo espírito científico", o observador já está implicado no campo da observação, de que sua intervenção modifica o objeto de estudo, transforma-o. Mesmo quando o esquece, o analista é sempre, pelo simples fato de sua presença, um elemento de campo (Lourau, 2004c, p. 83).

A neutralidade, nesse sentido, não se apresentaria como algo a ser perseguido, mas como algo inexistente, uma ficção da ideologia cientificista (Lourau, 1981). Dada a sua inexistência, exige-se que o pesquisador analise e explicite suas próprias relações com as instituições que o atravessam, evidenciando implicações 
que podem ser de ordem econômica, ideológica, organizacional, material ou libidinal (Monceau, 2008).

Como lembra Silva (2007), Lourau alerta que "os pertencimentos e as referências institucionais dos sujeitos precisam ser explicitados para propiciar análise dos mesmos e não para favorecer um confessionário" (Silva, 2007, p. 111). Reconheço que a denúncia da impostura da neutralidade analítica e o destaque conferido à análise da implicação como uma atitude nova e não obscurantista por parte do pesquisador (Lourau, 1997) podem, inicialmente, soar como a promoção de uma abordagem narcísica do fazer científico, recheada de psicologismos e nutrida pelos recônditos subjetivos do pesquisador, o que pouco interessaria à comunidade científica. Entretanto é preciso não confundir a explicitação das condições de produção das pesquisas, o que supostamente deveria ser de interesse, com a psicologização do fazer científico, o que nem sempre assegura visibilidade à forma de intervir do pesquisador como elemento crucial do campo de interferências da pesquisa.

Trata-se, a meu ver, de um tensionamento sempre presente na comunidade científica: enunciar condições de produção, desde que não ameacem a legitimidade do fazer científico em geral. Evidentemente que, se a neutralidade é um dos baluartes fundantes da concepção de ciência em questão, essa enunciação arrisca deslegitimar o fazer científico. Mas haveria deslegitimação mais evidente do que a ocultação das condiçôes de produção da pesquisa? Em tom irônico, que lhe era peculiar, Lourau (2004c) dispara:

O importante para o investigador não é, essencialmente, o objeto que "ele mesmo se dá" (segundo a fórmula do idealismo matemático), mas sim tudo o que lhe é dado por sua posição nas relaçôes sociais, na rede institucional. A partir dessa perspectiva, fica evidente que a maior parte dos artigos que aparecem nas revistas acadêmicas - de sociologia ou de psicologia, por exemplo - são quase tão "sérios" como as seçōes de horóscopo dos jornais (p. 85).

Além do exposto, a própria aposta de Lourau (2004c) no descentramento do analista também afasta interpretações de cunho narcisista acerca do trabalho do pesquisador. Segundo a reversão epistemológica promovida pela análise institucional, é o analisador, em sua expressão de não conformidade com o instituído, que revela a natureza desse mesmo instituído. Nesse sentido, não é mais o analista que realiza a análise, mas o analisador, que pode ser uma pessoa ou situação, por exemplo. $\mathrm{O}$ autor recomenda, a propósito, que o analista não se esquive dos efeitos analisadores do dispositivo de intervenção (Lourau, 2004c).

O trabalhador-pesquisador pode ser considerado um desses analisadores na situação do dispositivo de intervenção, atravessado que é por instituições as mais 
variadas, como a ciência e outras mais diretamente relacionadas ao seu campo de trabalho e pesquisa, como a loucura, a família e a profissão. É inevitável que seu movimento sincrônico de trabalho e pesquisa coloque instituídos em questão. Ao mesmo tempo, o trabalhador-pesquisador é um analisador que põe em análise muitas questóes e situações que se colocam a todo pesquisador (Kohn, 2001). É inegável, entretanto, que a exigência de nomear e justificar escolhas no âmbito da pesquisa, nesse caso específico, seja intensificada.

Em contraposição ao distanciamento, é possível que se argumente que o engajamento do trabalhador-pesquisador em relação ao seu objeto e seu campo de pesquisa possa resultar em comprometimento da atividade científica. Essa preocupação geralmente se volta para a dimensão ideológica que poderia se impor nesse caso. Se a ciência é considerada um acontecimento social e inegavelmente ideológico, o deslocamento da ideia de objetividade, não realizável, para a ideia de objetivação, critério mais importante de cientificidade, como sugere Demo (1985), pode ser apropriado. Segundo o autor, a objetivação seria entendida como "o esforço e o processo interminável e necessário de atingir a realidade, mais do que retratos fidedignos" (Demo, 1985, p. 71). Mas ele também afirma:

Ao reconhecermos que as ciências sociais são necessariamente ideológicas, não queremos ideologizá-las; queremos desideologizá-las; apenas, isto não traz a eliminação da ideologia, mas a convivência crítica, capaz de colocá-la na construção científica como parte menor (Demo, 1985, p. 72).

Não me parece plausível considerar que o poder ou a ideologia possam comprometer o rigor científico a priori. Como nos lembra Monceau (2008), a questão não é nos livrarmos de nossas ideologias, mas tentar analisá-las coletivamente: aí está o verdadeiro trabalho científico. Voltarei à questão do coletivo no próximo tópico, mas adianto que ela se coloca como uma perspectiva de agenciamento do trabalho investigativo do pesquisador, particularmente do trabalhador-pesquisador.

Também o referido engajamento do trabalhador-pesquisador não se confunde com a própria implicação, cuja análise propõe Lourau (1981). Engajamento e envolvimento admitem uma perspectiva voluntarista que se distingue do caráter irrevogável da implicação, que existe mesmo que não a desejemos. Albarello (2004), por exemplo, toma o sentido de implicação em seu senso comum quando atesta que um expert externo, diferentemente do trabalhador-pesquisador, não está, de forma alguma, implicado no campo. O uso institucionalista da implicação não admite tal situação. Queiramos ou não, estamos implicados, a questão é analisar mais o modo de implicação, sempre existente, do que sua existência ou quantidade, visto não poder ser medida (Monceau, 2008). Em perspectiva 
quantitativa, Albarello (2004) indica, mais de uma vez e de diferentes formas, os riscos de "implicação excessivamente forte" (Albarello, 2004, p. 29, tradução nossa) por parte do trabalhador-pesquisador. Ante tal "excesso", só caberia o distanciamento.

Entretanto pode haver dificuldades à análise da implicação. A maior delas seria a sobreimplicação, situação à qual também está sujeito o trabalhadorpesquisador. A sobreimplicação, uma deriva do conceito de implicação, é nutrida, segundo Lourau (2004a), pelo plus identificado no sobretrabalho, na produção da mais-valia ou na rentabilidade suplementar. Ela pode ser "composta igualmente de virtudes exigidas dos empregados, hierarquizadas em grades de avaliação" (Lourau, 2004a, p. 192). Cabe ressaltar a dimensão da exploração da subjetividade a que se refere o conceito, que deixa claro o vínculo entre subjetivismo e instrumentalismo (Lourau, 2004a).

É possível imaginar que um trabalhador-pesquisador possa ter, por exemplo, grandes dificuldades de analisar sua relação com a organização que tanto lhe remunera e garante sua sobrevivência, quanto lhe encomenda, subliminarmente, certa sobreimplicação. Muitas vezes, a sobreimplicação é condição de sobrevivência na própria organização, o que pode ser expresso na máxima "ame-a ou deixe-a".

Penido e Machado (2017) ponderaram que não seria surpresa se o esforço analítico de pesquisas-intervenção realizadas por trabalhadores-pesquisadores inviabilizasse sua permanência na organização ou na política pública em questão, apontando para a complexidade e o risco da análise das implicaçóes como prática social. Esse imbróglio se faz nítido na epígrafe que Lourau (1996) escolhe para abrir seu livro Intervençôes socioanalíticas: os analisadores da Igreja (tradução livre):

Uma instituição é perdida quando aquele que está dentro, em vez de se achar muito honrado, começa a pensar [. . .] Quando, no lugar de estar dentro de sua instituição, de ser, estar e viver e de funcionar simplesmente, como instituído, naturalmente [. . .]; quando a instituição não lhe basta mais [. . .] Quando ele começa a pensar, quando ele começa a se perguntar se ele não é uma besta velha [. . .] (Charles Péguy apud Lourau, 1996, epígrafe, tradução nossa).

Diante do exposto até aqui, retomo as considerações de Albarello (2004) sobre a complementaridade dos polos do engajamento e do distanciamento, e a necessidade de equilíbrio dialético entre tais polos no exercício científico do trabalhador-pesquisador. Parece-me que o problema é que o distanciamento, solução proposta para equilibrar a situação de engajamento do trabalhadorpesquisador, tem como efeito justamente a suspensão da análise do próprio engajamento, que não se apresenta da mesma forma para cada trabalhadorpesquisador e pode recobrir uma modalidade de implicação importante na 
construção do conhecimento em questão. Nesse sentido, contribui para que formas de relação com a instituição sejam desconsideradas na análise da composição do campo de interferências da pesquisa.

Mas o distanciamento não seria condição para a própria análise da implicação? Se a análise da implicação fosse tarefa privada do trabalhador-pesquisador, talvez isso pudesse ser alegado como uma perspectiva. Entretanto é preciso lembrar que a análise da implicação é coletiva (Lourau, 2004b) e demanda, em vez de distanciamentos, cruzamentos múltiplos e dispositivos que os ativem, como sinalizaremos a seguir.

\section{UM DISPOSITIVO AGENCIADOR DA ANÁLISE COLETIVA DA IMPLICAÇÃO DO TRABALHADOR-PESQUISADOR: A ESCRITA DIARÍSTICA}

Compreendo que os dispositivos que a análise institucional aponta para a análise da implicação apostam no plano coletivo que eles agenciam. Lourau (1998-1999) entende por dispositivo uma estrutura-ação que organiza o porvir. Não se trata de algo estrutural, mas operacional. Entre esses dispositivos, destacamos a escrita diarística, por seu potencial de ativar a dimensão relacional que agencia um plano coletivo para a análise da implicação do trabalhadorpesquisador.

Os diários dos pesquisadores costumam ocupar um lugar marginal em relação à pesquisa publicada, o que reduz significativamente a discussão sobre as condições de produção da pesquisa. Seguro da potência da escrita diarística para a análise da implicação, Lourau (2004b) convida o pesquisador a transformar o que chama de "extratexto da escritura diarística, com ou sem forte coloração intimista" (p. 251) em procedimento de trabalho, transportando-o "para longe dos recônditos da introdução, das notas de pé de página ou de fim de capítulo, dos anexos e partes documentais, etc., até atingir a página plena do texto" (p. 252). Para o autor, o diário permite que se conheça a pesquisa despida da “indumentária de domingo" (Lourau, 1993, p. 79), fazendo clara referência à desnaturalização das instituições que ele pode promover, incluindo a própria atividade científica.

As possíveis interpretações de cunho narcisista acerca da análise da implicação do trabalhador-pesquisador, apontadas no tópico anterior, também se aplicam ao uso do diário. $\mathrm{O}$ trabalhador-pesquisador muitas vezes se vê entre a necessidade de descrever sua implicação e o medo de se derramar na exibição de si, situação indicada por Lavergne (2007). O uso do diário como artifício para a análise da 
implicação, entretanto, não se caracteriza por um arroubo narcísico, mas serve para deslocar o pesquisador do centro, incluindo-o no campo de interferências da pesquisa, o que dá visibilidade à escrita como atravessada pela complexidade institucional.

Em contínuo movimento, o diário fornece lastro para os leitores construírem suas próprias intervenções sobre a análise de implicação do trabalhadorpesquisador. De alguma forma, esses leitores (que podem ser o orientador, os membros da banca, colegas da universidade, do serviço e tantos outros) sobrescrevem seu texto e dão continuidade à análise do hipertexto do campo de forças institucionais em questão. Para além de um somatório de leitores ou pessoas, que se conectam a partir do texto, antes extratexto, constata-se um cruzamento de instituições que atravessam o indivíduo e a sociedade, os leitores e os trabalhadores-pesquisadores.

Há uma frase lembrada de memória por Monceau (2008) que, segundo ele, Lourau repetia frequentemente: "A instituição fala pelo ventre, falando por nossa boca” (p. 21). Nessa afirmação, Lourau não deixa dúvida quanto a certa liquefação da dicotomia indivíduo-sociedade, o que reforça uma dimensão também social da escrita diarística, ainda que realizada por um indivíduo.

Partindo da necessidade de superação dessa dicotomia indivíduo-sociedade, Escóssia e Kastrup (2005, p. 302) avançam, ao afirmarem que ela implica uma nova abordagem da noção de relação, que não se daria a partir da interação desses termos constituídos, indivíduo e sociedade, mas por meio de um plano relacional produtor dos termos: "A relação, entendida como agenciamento, é o modo de funcionamento de um plano coletivo, que surge como plano de criação, de coengendramento dos seres" (Escóssia \& Kastrup, 2005, p. 302). Por derivação, é possível dizer que o trabalhador-pesquisador, por meio do seu diário, ativa a dimensão relacional que agencia um plano coletivo.

Albarello (2004), todavia, aponta a importância da escrita, para o trabalhadorpesquisador, como exercício de distanciamento. Ele parte do pressuposto de que, "se a palavra é da ordem da ação, a escrita é fundamentalmente da ordem da pesquisa" (Albarello, 2004, p. 9). Este é o ponto de maior dificuldade dos trabalhadores-pesquisadores, que, em seu local de trabalho, estão mais habituados a certa cultura oral ou a textos mais curtos (Albarello, 2004). Nesse sentido, o autor apresenta a escrita como forma de se extrair da ação imediata, o que seria uma importante competência a ser desenvolvida pelo trabalhador-pesquisador.

Diferentemente, compreendo que a escrita, em Lourau (2004b), cumpre uma função de dar passagem ao coletivo e não de extrair o pesquisador da ação imediata. Não se trata de extrair, mas de incluir em plano relacional. Concebido 
dessa forma, é como se o trabalhador-pesquisador assumisse cada vez mais a ancoragem que lhe constitui e, partindo dela, convocasse um coletivo a analisar suas relaçóes com as instituições que falam por sua boca ou, se preferirem, por sua caneta. Isso vale tanto para a escrita do diário quanto da dissertação ou tese, pois a proposta é que o texto do primeiro penetre e componha o das últimas. Afinal, é o entrecruzamento das implicações de toda ordem que produzem o fazer científico.

\section{CONSIDERAÇŌES FINAIS}

No fim das contas, falamos sobre modelos de ciência. Há aqueles que interrogam as práticas de pesquisa e os que sequer as interrogam. E os que as interrogam quase sempre o fazem com base em pressupostos como a neutralidade do pesquisador ou o distanciamento entre pesquisador e objeto. $\mathrm{O}$ estatuto do trabalhador-pesquisador, muitas vezes, estimula questionamentos baseados em tais pressupostos.

Penido e Passos (2019) observam que há certo preconceito na academia em relação ao trabalhador-pesquisador, expresso na crença de que sua prática científica seria mais pertinente aos mestrados profissionais. Nesse mesmo sentido, observo que a discussão sobre os desafios de se pesquisar o próprio trabalho costuma se fazer mais presente em dissertações e teses do que em artigos, o que aponta para certa esquiva da temática nos meios mais valorizados de divulgação científica. É certo que desnaturalizar os "múltiplos sentidos cristalizados" (Rodrigues \& Souza, 1987) das instituições, a começar da própria ciência, não é tarefa simples. A discussão sobre o trabalhador-pesquisador se insere nessa seara.

Em tempos de exceção como o que vivemos atualmente no Brasil, em que se pretende hipocritamente (porque de forma ideológica) varrer a ideologia da sala de aula, da ciência, da política e, por que não, da vida, revisitar o estatuto de trabalhador-pesquisador afirmando sua potência criativa e coletiva é uma forma de resistir. É preciso desnaturalizar a imposição de que a ciência exige distanciamento do objeto, sob pena de banirmos da comunidade científica os trabalhadores-pesquisadores e seus problemas cheios de vida. Afinal, a ciência também pode ser instrumento de exclusão e violência. 


\section{REFERÊNCIAS}

Albarello, L. (2004). Devenir praticien-chercheur: comment réconcilier la recherche e la pratique sociale. Bruxelles: Éditions De Boeck Université.

Altarugio, M. H. \& Capecchi, M. C. V. M. (2016). Sociodrama pedagógico: uma proposta para a tomada de consciência e reflexão docente. Alexandria: Revista de Educação em Ciência e Tecnologia, 9(1), 31-55.

Barel, Y. (1982a). Le paradoxe et le système: essay sur le fantastique social. Grenoble: Presse Universitaire de Grenoble.

Barel, Y. (1982b). Les enjeux du travail social. Action et recherche sociales, 3.

Casellas-Ménière, M. F. (2001). Histoire d'un trait d'union. In M. P. Mackiewicz (Org.), Praticien et chercheur: parcours dans le champ social. (pp. 39-40). Paris: L'Harmattan.

Dalpiaz, L. H. (2017). Participação, educação não escolar e problematização de práticas: uma perspectiva em elaboração. Espaço Pedagógico, 24(2), 265-280.

Demo, P. (1985). Introdução à metodologia da ciência. São Paulo: Atlas.

Drouard, H. (2006). Chercheur et praticien ou praticien-chercheur? Esprit Critique, 8(1). Recuperado a partir de http://espritcritique.uiz.ac.ma/Dossiers/ article.asp? t03 code $=8 \&$ varticle $=$ esp 0801 article $07 \& v$ rep $=0801$

Elias, N. (1983). Engagement et distanciation. Paris: Fayard.

Escóssia, L. \& Kastrup, V. (2005). O conceito de coletivo como superação da dicotomia indivíduo-sociedade. Psicologia em Estudo, 10(2), 295-304.

Fortuna, C. M., Matumoto, S., Mesquita, L. P., \& Monceau, G. (2016). A análise da implicação de pesquisadores em uma pesquisa-intervenção na Rede Cegonha: ferramenta da análise. Caderno Saúde Pública, 32(9), 1-10.

Jesus, J. C. O., Michinel, J. L., \& Burnham, T. F. (2012). Decifra-me ou te devoro! In T. F. Burnham (Org.), Análise cognitiva e espaços multirreferenciais de aprendizagem: currículo, educação à distância e gestãoldifusão do conhecimento. (pp. 177-191). Salvador: EdUFBA.

Kohn, R. C. (2001). Les positions enchevêtrées du praticien-qui-devientchercheur. In M. P. Mackiewicz, (Org.), Praticien et chercheur: parcours dans le champ social. (pp. 15-38). Paris: L'Harmattan. 
Lavergne, C. (2007). La posture du praticien-chercheur: um analyseur de l'évolution de la recherche qualitative. Recherches qualitatives (Hors Série), 3, 28-43.

Lourau, R. (1981). Le lapsus des intellectuels. Toulouse: Privat.

Lourau, R. (1993). Análise institucional e práticas de pesquisa. Rio de Janeiro: NAPE/UERJ.

Lourau, R. (1996). Interventions socianalytiques: les analyseurs de l'église. Paris: Anthropos.

Lourau, R. (1997). Implication transduction. Paris: Anthropos.

Lourau, R. (1998-1999). L'Assemblée Générale: genèse socianalytique d'un dispositif. Laboratoire d'analyse institutionnelle. Paris: Universite de Paris 8.

Lourau, R. (2004a). Implicação e sobreimplicacão. In S. Altoé (Org.), René Lourau: analista institucional em tempo integral. (pp. 186-198). São Paulo: Hucitec.

Lourau, R. (2004b). Implicação: um novo paradigma? In S. Altoé (Org.), René Lourau: analista institucional em tempo integral. (pp. 246-258). São Paulo: Hucitec.

Lourau, R. (2004c). Objeto e método da análise institucional. In S. Altoé (Org.), René Lourau: analista institucional em tempo integral. (pp. 66-86). São Paulo: Hucitec.

Lourau, R. (2004d). Uma apresentação da análise institucional. In S. Altoé (Org.), René Lourau: analista institucional em tempo integral. (pp. 128-139). São Paulo: Hucitec.

Monceau, G. (2008). Implicação, sobreimplicação e implicação profissional. Fractal Revista de Psicologia, 20(1), 19-26.

Penido, C. M. F. (2012). Análise da implicação de apoiadores e trabalhadores da estratégia de saúde da família no apoio matricial em saúde mental. (Tese de Doutorado). Universidade Federal de Minas Gerais, Programa de PósGraduação em Enfermagem, Belo Horizonte.

Penido, C. M. F., \& Machado, M. N. M. (2017). A pesquisa-intervenção institucionalista e o trabalhador-pesquisador: In I. C. F. Passos, \& C. M. 
F. Penido (Orgs.), Atenção psicossocial para crianças e adolescentes: pesquisaintervenção nas redes. (pp. 21-36). São Paulo: Zagodoni.

Penido, C. M. F., \& Passos, I. F. P. (2019). A potência da intervenção formativa de apoio matricial na produção de conhecimento em saúde mental. In S. M. Paulon, \& M. F. P. Londero (Orgs.), Saúde mental na atenção básica: o pesquisar como cuidado. (pp. 45-55). Porto Alegre: Rede Unida.

Rey, A. (Ed.). (1988). Le Robert micro. Paris: Dictionnaires Le Robert.

Rodrigues, H. B. C., \& Souza, V. B. L. (1987). A análise institucional e a profissionalização do psicólogo. In V. R. Kamkhagi, \& O. Saidon (Orgs.), Análise institucional no Brasil. (pp. 27-46). Rio de Janeiro: Espaço e Tempo.

Saint-Martin, C. (2013). Implication et surimplication du praticien-chercheur. Fractal, 25(3), 461-474.

Saint-Martin, C., Pilotti, A., \& Valentim, S. (2014). La réflexivité chez le doctorant-praticien-chercheur: une situation de liminalité. Revue $i$ Interrogations? 19. Recuperado a partir de https://www.revue-interrogations. org/La-reflexivite-chez-le-Doctorant

Silva, M. (2007). Reflexividade e implicação de um "pesquisador-nativo" no campo da saúde mental: sobre o dilema de pesquisar os próprios "colegas de trabalho". Campos, 8(2), 99-115.

Silva, R. B., \& Carvalhaes, F. F. (2016). Psicologia e políticas públicas: impasses e reinvenções. Psicologia \& Sociedade, 28(2), 247-256.

Torres, M. M., \& Lanza, L. M. B. (2013). Revista Argumentum, 5(1), 197-215.

Zaluar, A. (1986). Teoria e prática do trabalho de campo: alguns problemas. In R. Cardoso (Org.), A aventura antropológica. (pp. 107-126). Rio de Janeiro: Paz e Terra. 